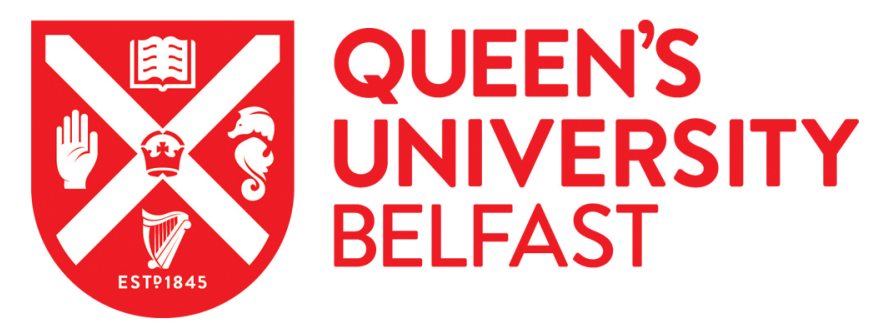

\title{
Utilising a computer game as a therapeutic intervention for youth in residential care: Some preliminary findings on use and acceptability
}

Aventin, Á., Houston, S., \& Macdonald, G. (2014). Utilising a computer game as a therapeutic intervention for youth in residential care: Some preliminary findings on use and acceptability. Children and Youth Services Review, 47(3), 362-369. https://doi.org/10.1016/j.childyouth.2014.10.012

Published in:

Children and Youth Services Review

Document Version:

Peer reviewed version

Queen's University Belfast - Research Portal:

Link to publication record in Queen's University Belfast Research Portal

\begin{abstract}
Publisher rights
Copyright @ 2014 Elsevier Ltd. This is the author's version of a work that was accepted for publication in Children and Youth Services Review. Changes resulting from the publishing process, such as peer review, editing, corrections, structural formatting, and other quality control mechanisms may not be reflected in this document. Changes may have been made to this work since it was submitted for publication. A definitive version was subsequently published in Children and Youth Services Review, vol 47, part 3, December 2014, doi:10.1016/j.childyouth.2014.10.012.

\section{General rights}

Copyright for the publications made accessible via the Queen's University Belfast Research Portal is retained by the author(s) and / or other copyright owners and it is a condition of accessing these publications that users recognise and abide by the legal requirements associated with these rights.
\end{abstract}

\section{Take down policy}

The Research Portal is Queen's institutional repository that provides access to Queen's research output. Every effort has been made to ensure that content in the Research Portal does not infringe any person's rights, or applicable UK laws. If you discover content in the Research Portal that you believe breaches copyright or violates any law, please contact openaccess@qub.ac.uk. 


\section{Using a computer game as a therapeutic intervention for young people in residential care: Some preliminary findings on use and acceptability}

Mental illness is extremely common among young people living in residential care. However, many are reluctant to avail of therapeutic treatment. The value of using computer games as therapeutic tools for these young people has received very little attention, despite indications of their potential for promoting engagement in therapeutic work and improving mental health outcomes. This study aimed to fill this research gap through the development, introduction, and preliminary evaluation of a therapeutic intervention in group care settings. This intervention incorporated a commercially available computer game (The SIMS Life Stories ${ }^{\mathrm{TM}}$ ) and emotion regulation skills coaching. Qualified residential social workers were trained to deliver it to young people in three children's homes in Northern Ireland, where therapeutic approaches to social work have recently been introduced. The research was framed as an exploratory case study which aimed to determine its acceptability and potential therapeutic value. Computer-game based interventions appear to have value for use as therapeutic tools in group care settings and deserve further development and empirical investigation to determine their effectiveness in improving mental health outcomes.

Keywords: Maltreated Youth, Residential Child Care, Group Care, Adolescents, Computer-Assisted Interventions 


\section{Introduction}

\subsection{Mental Health of Maltreated Youth}

Adolescents living in public care are considered especially vulnerable to mental health difficulties, due to their experiences before and after entry into the care system. These often include exposure to multiple traumatic events in childhood and possible negative experiences in the care system such as placement instability, bullying, and the absence of a consistent adult confidant or advocate (Milburn et al., 2008; Hannon et al., 2010; Uliando \& Mellor, 2012). Such experiences can have a devastating impact on psychosocial development and long-term mental health outcomes, and research suggests that many adolescents in care have a high incidence of mental health disorders (Meltzer et al., 2003; Cousins et al., 2010; Heneghan et al, 2013). In a study undertaken by the Office for National Statistics (ONS), 45\% of those aged 5-17 in public care in England were found to have a mental health disorder (Meltzer et al., 2003). This is almost five times higher than the rate for adolescents living in private households (Green et al., 2005). Relatedly, in a US study (Havlicek et al, 2013), young people in foster care aged 17 or 18 were two to four times more likely to experience lifetime and/or past year mental health problems compared to young people in the general population of a similar age. Another US study (Petrenko et al, 2011) identified 22\% of children in an out-ofhome cohort had unmet mental health needs.

The prevalence of mental health disorder among adolescents in residential care placements is even more striking. The ONS study (Meltzer et al., 2003) indicated that as many as $70 \%$ of adolescents in residential care homes in England had a mental health disorder and other studies have reported rates as high as 97\% (McCann et al., 1996). Additionally, studies which examined the impact of childhood maltreatment, such as abuse and neglect, on mental health outcomes have indicated a wide range of emotional and psychological problems ranging from attachment difficulties (Schofield \& Beek, 2005; Bentovim, 2006; Tanner \& Turney, 2006; Fearon et al., 2010) and problems regulating emotions (Cimmarusti, 2011) to mental health disorders and suicidal ideation (Skowron \& Reinemann, 2005). 
Research has also indicated that adolescents in care have poor long-term mental health outcomes, including a greatly increased likelihood of social exclusion, attempted suicide, drug and alcohol abuse, homelessness and progression to different types of institutional care (such as psychiatric hospitals and prisons) over time (Utting et al., (1997). Warren (1999) found that adolescents in foster care were fifty times more likely than those who had never been in care to have a mental illness and their own children were sixty times more likely than their peers to be living in public care (cited in Iwaniec, 2006: 9).

Unlike the rest of the UK, there has been no national survey of psychiatric morbidity among adolescents in care in Northern Ireland (Macdonald et al., 2011) and research has been confined to small-scale local studies in which similar rates of mental health disorder to those noted above have been reported (Teggart \& Menary, 2005; Cousins et al., 2010). Although rates of mental health disorder among adolescents in care in Northern Ireland are thought to be similar to rates in Great Britain, higher levels of social deprivation, and the history of civil conflict in this jurisdiction, have been implicated as exacerbating factors (McAuley \& Young 2006; Davren, 2007; Commission for Victims \& Survivors; 2010; DHSSPS, 2011a).

\subsection{Treatment Gap}

Despite such high levels of mental health need, many adolescents in care are reluctant to engage in traditional, psychotherapeutic work. The reasons for this include the difficulty identifying the symptoms of mental health (Tylee et al., 2007) and the labelling and stigmatisation associated with availing of mental health services (Anderson \& Lowen., 2010; Gulliver et al., 2010). In addition, some adolescents feel such services are seldom designed nor delivered with their interests in mind (VOYPIC, 2006; Tylee et al., 2007). This has led to a recognised need for innovative interventions which are both effective and capable of engaging adolescents in a therapeutic process (Bamford, 2006; Macdonald et al., 2011). The development of such interventions has posed challenges for practitioners and researchers alike. However, some have reported success with strengths-focused, opportunity-led, and activity-based responses that normalise therapy and, at the same time, help 
adolescents develop skills and build resilience (Saleebey, 2002; Blaustein \& Kinniburgh, 2007; Ward, 2007; Unger, 2013). Additionally, it has been suggested that there is a need to expand the definition of therapy so that all activities can be considered to have therapeutic potential if used in an appropriate way (Ward, 2007).

Related to this view is a recognised need for community-based, mental health services and innovative interventions which are deliverable in 'real-world' settings. In this connection, residential care homes are increasingly seen as potential sites for the provision of mental health services and it has been suggested that residential care staff could extend their roles to include work with a more overt, therapeutic slant (Gibbs \& Sinclair, 1999; Nunno et al., 2003). In order to develop this potential, The Department of Health, Social Services and Public Safety Northern Ireland (DHSSPS) has recently provided funding to establish therapeutic approaches in residential children's homes across Northern Ireland (Macdonald et al, 2012).

\subsection{Computer Games as Therapeutic Tools}

The computer game is one medium that may have therapeutic potential with adolescents in care. In this connection, recent decades have seen significant developments in the field of computer game technology. There have also been increasing reports of the benefits of computer games in improving health-related outcomes and promoting adolescents' engagement and motivation (Griffiths, 2003; Caspar, 2004; Kato et al., 2008; Wilkinson et al., 2008; Primack et al., 2012). Computer games are an integral part of contemporary youth culture in western society and offer the potential for normalising the therapeutic process, thereby increasing the possibility of engaging adolescents. Additionally, because of their essentially informal nature, such interventions might be amenable to opportunistic delivery by residential social work staff within children's homes. There is, however, a dearth of computer-game based interventions suitable for use in specialist group care settings. This study addressed this research gap by developing, introducing and evaluating one such intervention in a number of children's homes in Northern Ireland. 


\subsection{The SIMS Intervention}

The intervention, which was developed by the first author, comprised two core elements: (a) the young person playing a commercially available, leisure-oriented computer game (The SIMS Life Stories $^{\mathrm{TM}}$ ) and (b) a residential social worker delivering emotion regulation skills coaching to the adolescent during the course of the game (see Figure 1). The intervention was preceded by training for the residential social workers, and latterly accompanied by clinical supervision, technical support and a detailed user-manual (which included 'visual aids' for teaching young people about emotion regulation). The basic idea was that a residential social worker used scenarios from the game to model and discuss the identification, modulation and expression of emotions with the young person. Broadly based on the Attachment, Self-Regulation and Competency (ARC) model of intervention for complexly traumatized youth (Kinniburgh et al., 2005), it was intended to encourage engagement of young people in the therapeutic process and increase their emotion regulation skills.

Figure 1

The composition of the intervention

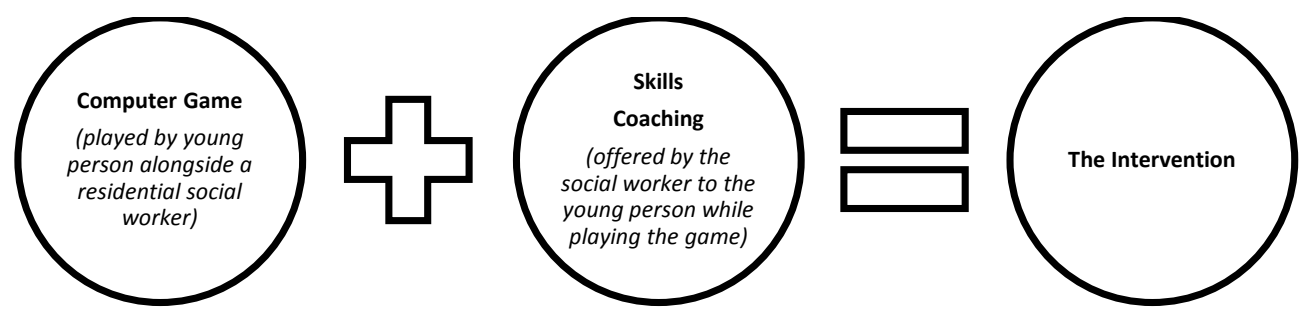

The design and development of the intervention was an iterative process that involved generating ideas from reviews of the literature, consultation with key stakeholders regarding the appropriateness of these ideas, re-visiting the literature in order to refine ideas, and further consultation regarding the refinements. The process is reported elsewhere ( ). 


\subsection{Outline of the Study}

The dimesnion of the study described in this paper aimed to ascertain residential social workers' and adolescents' perceptions of the acceptability of the intervention; its potential therapeutic value; and the barriers preventing its successful implementation. Based on this aim, the research design and choice of methods were informed by two sources: (a) the UK Medical Research Council's (MRC, 2008) guidance on the development and evaluation of complex interventions and (b) case study methodology (Stake, 1995; Yin 2009, Simons, 2009). Ethical approval was gained from Queen’s University Belfast, the Research Governance Department of the Health and Social Care Trust in which the research took place, and the Office of Research Ethics Northern Ireland. Pertinent here, was gaining meaningful consent from the young people and staff to participate in the study.

The Team Leaders (Managers) of all four medium and long-term statutory children's homes in one of the five Health and Social Care Trust areas in Northern Ireland were invited to take part in the research. They were pragmatically sampled because the children's homes (in the particular Trust area) were accessible to the researcher (via the consultant clinical psychologist involved in the development of the intervention) and had resident young people who were likely to be in placement for the duration of the study).

Three of the four homes agreed to participate. All were six-bed purpose-built facilities situated on the outskirts of three large towns. The Willows and the Laurels were long-term units (providing placements of 18-months or longer) and the Beeches was an intensive support unit (aiming to provide intensive, therapeutic support for periods of between 6 and 18 months). Aside from this core difference (and a corresponding distinction in purpose and function), the three homes were very similar in terms of length of operation, staffing structure and the profile of staff and residents (see Table 1). 
Table 1 - Overview of the participating children's homes*

\begin{tabular}{|c|c|c|c|}
\hline & WILLOWS & LAURELS & BEECHES \\
\hline Opened & 2002 & 1999 & 2003 \\
\hline Classification & Long-term unit & Long-term unit & Intensive support unit \\
\hline $\begin{array}{l}\text { Number residents in } \\
\text { placement at start of } \\
\text { research }\end{array}$ & 6 & 4 & 5 \\
\hline Age range residents & $15-17$ & $14-16$ & $12-17$ \\
\hline Sex residents & 4 male; 2 female & 2 male; 2 female & 3 male; 2 female \\
\hline $\begin{array}{lr}\text { Number } & \text { qualified } \\
\text { residential } & \text { social } \\
\text { workers (RSWs) }\end{array}$ & 9 full-time & $\begin{array}{l}7 \text { full-time } \\
2 \text { part-time }\end{array}$ & 9 full-time \\
\hline $\begin{array}{l}\text { Number residential } \\
\text { support workers }\end{array}$ & 1 full-time & 1 full-time & 3 full-time \\
\hline
\end{tabular}

*Pseudonyms are used for the children's homes and research participants.

All staff and young people in the three homes were invited to participate, on an opt-in/out basis, in the following process:

1. Onsite training sessions with staff regarding the use of the SIMS intervention as a therapeutic tool. (Training was mandatory for those intending to deliver the intervention).

2. Delivery of the SIMS intervention by the key worker to the young people over six, one hour sessions.

3. Carrying out a semi-structured, post-intervention interview with the staff and the young people exploring their experience of using the intervention.

Table 2 below illustrates how the staff and young people participated in the research. A total of twenty-one residential social workers were recruited and trained to deliver the SIMS intervention. Training sessions provided participants with an overview of the following areas: (a) complex trauma, its psychological and developmental implications and relevance to adolescents in care (b) the therapeutic approach (skills-oriented, present-focused) and rationale for focus on self-regulation skills (c) the components of intervention (The SIMS game and skills coaching) and an opportunity to practice delivering it and (d) their role in delivering the intervention (what to do and what not to do). 
Table 2 - Participation of staff and young people in the research

\begin{tabular}{|c|c|c|c|}
\hline & WILLOWS & LAURELS & BEECHES \\
\hline \multicolumn{4}{|l|}{ STAFF MEMBERS } \\
\hline $\begin{array}{l}\text { Attended information } \\
\text { session }\end{array}$ & $\begin{array}{l}\text { Team Leader (TL) } \\
6 \text { RSW }\end{array}$ & $\begin{array}{l}\text { Deputy TL } \\
4 \text { RSW }\end{array}$ & TL only \\
\hline $\begin{array}{l}\text { RSWs taking part in } \\
\text { training }\end{array}$ & 7 & 6 & 8 \\
\hline $\begin{array}{l}\text { RSWs agreeing to deliver } \\
\text { the intervention }\end{array}$ & 5 & 2 & 4 \\
\hline $\begin{array}{l}\text { RSWs delivering at least } \\
\text { one session }\end{array}$ & 4 & 2 & 2 \\
\hline $\begin{array}{l}\text { RSWs taking part in } \\
\text { post-intervention } \\
\text { interview }\end{array}$ & 3 & 1 & 0 \\
\hline YOUNG PEOPLE & & & \\
\hline $\begin{array}{l}\text { Initially agreeing to } \\
\text { participate }\end{array}$ & 5 & 2 & 4 \\
\hline $\begin{array}{l}\text { Taking part in at least } \\
\text { one session }\end{array}$ & 4 & 2 & 2 \\
\hline $\begin{array}{l}\text { Taking part in post- } \\
\text { intervention interview }\end{array}$ & 3 & 1 & 0 \\
\hline
\end{tabular}

Eleven RSWs who had attended the training agreed to deliver the intervention on a one-to-one basis to residents. Four delivered more than one session. A total of eleven young people agreed to participate and four engaged in more than one session. One home withdrew from participation in the study at the beginning of the implementation stage. After the implementation sessions, the residential social workers and young people were invited to participate in a semi-structured interview regarding their views on the strengths and weaknesses of the intervention, experiences using it, perceptions of its therapeutic value, and barriers and facilitators of successful implementation (i.e. fidelity to implementation protocol). Interviews with them were tape-recorded and subjected to a thematic content analysis using an abbreviated version of grounded theory (Glaser \& Strauss, 1967) to code, categorise and organise the data into themes and overarching themes. The findings across data sources were compared to determine overall perceptions of the acceptability of the intervention. 


\section{Results}

\subsection{Perceptions of the Intervention}

Three themes relating to perceptions of the intervention (acceptability, perceived therapeutic value and perceived barriers to successful implementation) indicated the importance of informal, flexible, and adaptable interventions which were compatible with individual needs and ways of working in the homes. In presenting the data below, pseudonyms for the young people are formatted in italics and, for key workers, in bold italics.

\subsubsection{Acceptability}

Although one young person said that he did not like the game, most of those at the Willows who used the intervention expressed positive views regarding its acceptability, noting only minor dissatisfaction with issues such as the length of time needed for preparation.

At the Willows, the intervention as a whole was viewed as: "good" (Sam, PI, 8); "really good" (Andy, PI, 9); “something different”, “interesting” (Paul, PI1, 17); and “fun” (Caroline, PI, 9). Paul suggested that one of its major strengths was that it did not appear overtly therapeutic.

[...] that's a strength of the work too in that the young person wouldn't see it as therapy and the worker wouldn't see it as therapy either. You know sitting down on the sofa and it's not formal at all you know. (Paul, PI1, 69)

At the Laurels, the participants indicated dissatisfaction with the skills coaching component, a perceived lack of fit with the adolescents' needs, and the general lack of motivation to engage on the part of adolescents. Joe said that while he thought the intervention was novel, he did not find it appropriate for use at the Laurels because he felt the game was not street-wise enough for 'high risk' 
adolescents and more suitable for younger children. Additionally, he did not consider it to be consistent with Oliver's needs:

I identified some concerns about [Oliver] and actually his participation before [implementation] and thought that it wouldn't be right for [Oliver's] particular needs. Em, some aspects of that were wrong and some were right. [Oliver] did engage with it [for] a prolonged period, but completely at his own determination. He would only do it on his own and wouldn't engage in the dialogue that would be associated with a sort of more therapeutic response. (Joe, PI, 7)

Some RSWs felt that the characteristics of the individual adolescents would impact on their engagement. During the training many stated that they did not think their young person would engage easily due to a lack of motivation, lack of interest in computer games or because they would not commit to therapeutic work. They indicated that, even if they did engage, it would not be for an extended period. One residential social worker said that "commitment is an issue for these young people” (FN, 23.07.10).

A lack of fit with the identified needs and abilities of the adolescents, in particular those with learning disabilities, were also highlighted as challenges at the Beeches. In addition, the complexity of the life space impacted adversely on whether the intervention was deemed to be acceptable. While both staff and adolescents thought it was a desirable idea, a shift in priorities (and the atmosphere of the unit) meant that it was no longer viewed positively for use at that time.

For the adolescents at the Willows, the game was the intervention and none of them seemed to attach much significance to the social worker's presence or attempts at skills coaching.

Both Andy and Sam expressed generally positive attitudes and both said they had found the game educational:

R: Would there be anything you'd change about the game or if you could create your own game or that kind of thing would there be anything that you would change or add in to it? 
Andy: No I thought it was all really well put together. I'd use it like.

R: Would you? Okay. Could you, 'cause I know you play computer games, would there be any other computer games that you would suggest that would be useful in that same kind of way as well.

Andy: I don't think there's any for that kind of idea at the minute that's actually out. A lot of the ones that are out are like violent and shooting and things like that, which a lot of young people are into and I think we need to change that. I think there needs to be more computer games out which are more interactive for young people rather than just crime and sex and things like that there. I think that should all change like. I think there should be more educational games out. (PI, 36-39)

At Laurels, Oliver said that he would play the game again and would recommend it to other adolescents:

R: So overall what did you think of it?

Oliver: It was good.

R. It was good? What did you like about it?

Oliver: The way you could do different things, around the house and that.

R: Em, anything you didn't like about it?

Oliver: No. [pause 2 secs]. I actually don't. It was good.

Despite Eoin's indications that he "hated" (PI, 31) the game and thought it was "a load of shite” (Eoin, PI, 8), Caroline was convinced that it was an important element of the intervention which she felt had engaged Eoin. Support for her conviction came from the fact that Eoin had played the game by himself on one occasion (Caroline, PI, 37). 
R: Just moving on to the intervention. Do you think it was useful for engaging [Eoin]?

Caroline: Yes. Probably. Yes.

R: Did you encourage him to come and do it or was it the fact that you were playing a game that engaged him?

Caroline: The game.

$R:$ The game?

Caroline: Definitely. (PI, 38-43)

The skills coaching component was deemed acceptable by all participants at the Willows. Paul and Andy were both comfortable sitting down together and Paul said there was "nothing" (PI1, 75) he would change about this aspect of the intervention because it was something he would do with Andy quite often. Andy said Paul's presence kept his “mind focused” (PI, 41) and Eoin said Caroline being there was a "sound auld job" (PI, 26).

Paul thought skills coaching was very much in line with his usual way of working:

Well as a residential social worker you're constantly working with the young people to get them to sit down in the first place and, you know, to spend time with you. Em, I suppose just direct work skills. (Paul, PI, 61)

Sam liked Paul being there because of the technical support he could offer:

R: You said you enjoyed the game. What about the fact that Paul was sitting down beside you doing it with you. What did you think of that?

Sam: Yeah it was good because staff use computers so they know what they are doing.

R: Uh-huh. Did you ever feel like aww, you know, "I'd just love to be playing by myself”? Sam: No. 
Unlike the staff and young people at the Willows, neither Joe nor Oliver at the Laurels found the skills coaching acceptable. Joe said he had to withdraw attempts at communicating with Oliver when he became angry:

$R$ : In terms of that first session whenever you tried to incorporate the skills coaching can you just tell me how that worked or didn't work?

Joe: It didn't work because other than explaining what the game was about and getting frustrated with me. You have to be very subtle with [Oliver] in terms of how you show an interest. What I was trying to do was sort of, obviously physically get alongside him and ask him to explain the game to me. He very quickly got cheesed off with my questions and got angry with my questions and 'f-ed' me off and wouldn't engage further. Em, and refused thereafter to speak to me while he was doing the game and other sessions or when he requested the laptop.

Oliver expressed a similar view, suggesting that "someone looking over [his] shoulder" and asking “stupid questions” was “annoying.

\subsubsection{Perceived Therapeutic Value}

Two sub-themes emerged relating to the 'potential uses' and 'potential therapeutic impact' of the intervention.

\section{Potential Uses}

An unexpected finding was that, in the long-term units, participants saw the value of the game beyond coaching emotion regulation skills, More specifically, they saw it as a tool for engaging in one-to-one work with a variety of different goals directly related to the social worker's perceptions of the current needs of the adolescents and the core function of the units: preparation for life after care 
through independent living skills coaching and diversion from risk-taking behaviour. Although intended to be used for coaching emotion regulation skills, none of the participants at Willows saw this as the game's primary use. Rather, adolescents considered it an enjoyable way of passing the time, a means of spending quality, one-to-one time with their key-worker and as a valuable tool for learning independent living skills. Residential social workers talked about the intervention as a funbased, engaging tool for getting to know adolescents; identifying deficits in emotion regulation skills; discussing 'real life' difficulties in a less threatening way; spending quality time with the young person; and engaging them more generally in therapeutic work.

Paul indicated that it offered a different tool for engaging in one-to-one work with Sam:

Sam would generally enjoy the one-to-one attention from staff, so you know, it provided an opportunity to do one-to-one with, you know, something different, you know, than the usual one-to-one work. (Paul, PI2, 21)

Sam appreciated the intervention as an enjoyable activity for passing the time:

R: Em. What did you like most about it?

Sam: The game just. It gave me something to do.

$R$ : It gave you something to do of an evening type of thing. Is that what you mean? Sam: Yeah.

$R$ : What would you normally be doing if you weren't playing the game?

Sam: Sitting around probably.

Andy thought the intervention had value as an activity for one-to-one work, because it gave him the opportunity to spend quality time with Paul.

At the Laurels, Joe felt the game alone was a useful tool for diverting Oliver from risk-taking behaviour:

I mean he's a high risk taker, major high risk taker. He's one of the highest categories within the Trust. There'd be a lot of concern about his behaviours and potential for misadventure or, 
you know, even disability or fatality in terms of his behaviours. So at least when he was engaging on a regular basis with the game and that did reduce his high risk behaviours. (Joe, PI, 7)

One RSW thought that the game would be useful for getting to know her key-child who had just recently moved into the unit (FN, 16.09.10) and another RSW felt it would be useful for teaching his key-child about independent living skills as he was going to be leaving the unit within the next couple of months (FN, 16.09.10). A third RSW thought the game would be useful for learning about the young person's priorities and seeing how patient they were (FN, 24.08.10).

The four adolescents who took part in post-intervention interviews had different perceptions of the value of the intervention. Unlike the RSWs at Willows, both Sam and Andy saw its primary use for getting them to think about independent living skills.

Andy felt it gave him insight into what life would be like when he was living independently:

It sort of gave me an insight to what I needed to actually do and whatever, whenever I go out into the world. (PI, 43)

\section{Therapeutic Impact}

While little therapeutic impact would be expected given the limited exposure to the intervention, and lack of fidelity to the implementation protocol, the social workers noted its potential for engaging adolescents in therapeutic work and building relationships. Some of the participants felt the intervention had had an impact on the relationship between the social worker and the young person. For example, Fiona thought that it had an impact on Sam and Paul's relationship:

$R$ : Do you think the intervention had any impact on Sam?

Fiona: Yes. I think it was useful for his relationship building with Paul who is his co-worker. I was actually surprised at how eager Sam was to do it at times. (PI, 35-36 
Both Andy and Sam highlighted another unintended impact, namely increased knowledge of what independent living might be like:

R: Okay. Em, do you think, because, you know you said earlier that the computer game was good at showing you everyday life, do you think it helped you in any way?

Sam: Yeah.

$R:$ In what way?

Sam: Like knowing what I'm gonna have to do if I'm goin' about on my own. Like going and buying groceries and paying bills and getting a job. (PI, 58-61)

While, on the one hand, Joe said that he did not think the intervention was appropriate for older teenagers, he conceded on the other that the game was useful for diverting Oliver from risk-taking behaviour and that it had served to help him modulate his anger:

When that game was being played in terms of, the SIMS game, he'd be very very focused on it and he was very calm. He wasn't agitated in any way when he was playing the game. (Joe, PI, 7-9)

Like Sam in Willows, Oliver saw the main value of the game as an enjoyable way of passing the time (PI, 66-69), although he agreed with his key-worker that it had reduced his risk-taking behaviour.

\subsubsection{Perceived Barriers to Engagement \& Successful Implementation}

The participants in all three homes noted the impact of contextual factors acting as barriers to successful implementation, reflecting the lack of fit between the implementation protocol and the residential child care context. Lack of time, inappropriate timing, the volatility of the life space, and the changing needs of the adolescents emerged as core findings. Additionally, the characteristics of 
individual adolescents and residential social workers were implicated as barriers to engagement, central among which was lack of interest and motivation to engage in therapeutic work.

Paul noted that Andy had "a lot going on" in his life at the time of implementation and although they seized opportunities whenever possible, other priorities relating to Andy's imminent move to independent living took precedence:

If I'm honest it wouldn't have been a huge priority. We would have played as much as we could but there was a lot going on for him the last six months. (Paul, PI1, 11)

Caroline suggested that supervision, and the inclusion of the intervention as part of the work plan, were essential for successful implementation. She said the researcher's input had kept her focused on the task.

$R$ : What about if it wasn't part of the research and I wasn't ringing asking how are you getting on and stuff. How do you think it would pan out in the end?

Caroline: Em. I think not a lot would go on. You'd need somebody that's gonna be checking up on you [...] you could make it, like you could have it as part of your monthly feedback and you'd have to report that you did something. Because it's, you know yourself, especially in [Willows]. You could be coming in and anything could happen. (PI, 24-27)

At the Willows, Paul said that successful implementation would depend on the characteristics of the individual young person and their relationship with the key worker and indicated that the work that could be achieved depended to large degree on Andy's mood.

Joe thought the overtly therapeutic focus of the intervention, plus past negative experiences with professionals, were barriers for Oliver: 
[Oliver] is very different from a lot of kids. He's a real individual when it comes to it. He's very self-determined. He's very headstrong. He doesn't like authority. He doesn't like therapeutic approaches. I can sort of understand, maybe, where he's coming from because he's had therapy to it's coming out of his ears...(Joe, PI, 25)

The characteristics of RSWs themselves were also mentioned as potential barriers to successful implementation. In particular, Paul noted the importance of whether or not the staff member had a preference for the practical aspects of their work rather than the therapeutic:

Paul: I suppose in general there would be staff here who would be into more therapeutic approaches than others and others would have a more practical outlook on residential so there might be some resistance to that. (PI1, 115-117)

Additionally, however, Paul indicated that implementation might conflict with the RSW role of disciplinarian and parent figure.

You know you're living with the young person so in one way you're the person whose imposing sanctions and discipline, you're sort of a parental figure, so they mightn't be able to sit down and open up. (Paul, PI1, 51)

Joe also talked about the disjuncture between the focus and structure of the intervention and current ways of working with Oliver:

[We have identified a] need for [Oliver] to be more deferred in his approach [i.e. to work on deferred gratification]. [...] This is what I have identified for [Oliver] and then the team has signed up to that. But what we have said is we don't use formal sessions. We look for informal opportunities to meet that particular need so that's how we work. (Joe, PI, 32) 


\section{Discussion}

Overall, uptake of the intervention was low and its use inconsistent. Participants offered a variety of reasons for this but on the whole indicated that this was not unusual in residential group care. RSWs took between four and eight weeks to begin using the intervention and although it was supposed to be delivered over a period of between six and twelve weeks, such were the impacts of time constraints and other priorities that one young person engaged in six sessions over an eleven month period. While some of these delays were related to external factors, such as LAC reviews, shared-care arrangements and staffing shortages, most were due to factors directly related to the RSWs active role in the life worlds of the adolescents, for example, 'bad' days, arguments, theory tests and other more pressing priorities relating to preparation for independence. This is in line with other research which indicates a lack of time for the provision of therapeutic work (Kilpatrick et al., 2008; Kendrick et al., 2005; Campbell \& McLaughlin, 2005), this study confirmed the potential impact of the RSWs multifaceted role on the use of the intervention during the study. This reflects the lack of fit between the implementation protocol and the context. Asking RSWs who were already pressed for time to take on additional responsibilities meant that implementation of the intervention was not prioritised.

This study provides preliminary evidence to suggest that the SIMS intervention in particular (and computer-game based interventions in general) may have potential for engaging adolescents in residential child care in therapeutic work. The findings imply a number of considerations which might serve as a guide to those wishing to develop and introduce computer games for therapeutic use in residential group care...

\subsection{Implications of the Findings}

For intervention development - informal, flexible and adaptable interventions attuned to the needs of individual young people. 
For successful implementation - training, supervision and additional resources for residential social workers emerged as important.

\subsection{Further Research}

This suggests that further research examining this, and similar, interventions would merit consideration. With regards to the intervention presented in the current study, further research is needed to evaluate its effectiveness and determine the underlying mechanisms of change. This process could begin with single-case evaluation studies which examine the impact of the intervention on emotion regulation skills (as well as general emotional wellbeing and perceptions of coping) in individual young people. Should such studies show positive impact, the feasibility of conducting more rigorous effectiveness research should be examined through a pilot randomised controlled trial with embedded process evaluation examining issues such as the feasibility of recruiting and retaining participants as well as the acceptability of the intervention in a wider range of children's homes.

Given that the intervention appeared to have a number of potential uses beyond that of coaching emotion regulation skills, further exploratory research could examine its value for different therapeutic outcomes such as problem-solving and consequential thinking as well as for different populations such as care leavers and those in foster care placements. Additionally, research should examine the value of other computer games in these contexts as well the value of using therapeutically-focused 'Apps' on devices such as mobile phones.

A significant gap in the research literature is the lack of prevalence data regarding rates of mental health disorder in general, and complex trauma symptoms in particular, among young people in care in Northern Ireland. Additionally, there is a need for systematic reviews of effective therapeutic interventions for this population, including computer-game based interventions for young people in residential care. This information would provide a solid foundation on which to base the development of complex interventions for young people in care. 
A primary empirical challenge remains regarding the development, evaluation and successful implementation of effective therapeutic interventions for use in residential child care settings. As noted above, due to the contextual, individual, intervention and research level challenges which resulted in implementation failure during the study, it was not possible to determine the potential therapeutic value of the intervention. This indicates that a primary challenge for researchers wishing to develop, introduce and evaluate the efficacy of therapeutic interventions for use in residential child care settings, is to ensure the development of interventions which are compatible with the context and the needs, expectations and values of users, and research protocols which are capable of maximising participants’ engagement.

Further research is needed as this exploratory study had several limitations...

\section{Conclusion}

Valuable insight has been gained into the use of The SIMS intervention and areas for future development and evaluation are identified. These preliminary findings suggest that computer game based interventions have potential as engaging and flexible approach to providing therapeutic treatment for maltreated youth. Further development work and research which can determine their therapeutic effectiveness is recommended.

\section{Acknowledgements}

This study was funded by the UK Economic and Social Research Council. The authors thank... Parts of this paper were presented at... 


\section{References}

Anderson, J. E., \& Lowen, C. A. (2010). Connecting youth with health services Systematic review. Canadian Family Physician, 56(8): 778-784.

Anglin, J.P. (2002). Pain, Normality and the Struggle for Congruence: Reinterpreting Residential Care for Children and Youth. New York: Haworth Press.

Bamford, D. (2006). The Bamford Review of Mental Health \& Learning Disability (Northern Ireland. Belfast: DHSSPS.

Bentovim, A. (2006). 'Therapeutic interventions with children who have experienced sexual and physical abuse in the UK'. In: C. McAuley, P. Pecora \& W. Rose (Eds.), Enhancing the Well-Being of Children and Families through Effective Interventions: UK and USA Evidence for Practice. London: Jessica Kingsley, 143-57.

Blaustein, M., Kinniburgh, K. (2007). Intervention Beyond the Child: The Intertwining Nature of Attachment and Trauma. British Psychological Society, Briefing Paper 26, 48-53. Accessed online October 2008: http://www.traumacenter.org/products/pdf_files/Intertwining_Nature_of_Attachment_and_Trauma.pd $\mathrm{f}$

Bolger, J. \& Millar, J. (2012). 'Residential Care in Practice’. In M. Davies (Ed.) Social Work with Children and Families. Basingstoke: Palgrave Macmillan, 304-322.

Campbell, A. \& McLaughlin, A. (2005). Views that Matter: Staff Morale, Qualifications and retention in Northern Ireland. London: NCB. 
Caspar, F. (2004). Technological developments and applications in clinical psychology and psychotherapy: Introduction. Journal of clinical psychology, 60(3): 221-238.

Cimmarusti, R. A. (2011). Increasing Emotional Regulation for Youths in Residential Care: Phases of Change. Residential Treatment for Children \& Youth, 28(2): 91-101.

Commission for Victims \& Survivors. (2010). Comprehensive Needs Assessment - First Interim Report. Belfast: Commission for Victims \& Survivors.

Cook, A., Spinazzola, J., Ford, J., Lanktree, C., Blaustein, M., Cloitre, M et al. (2005). Complex Trauma. Psychiatric Annals, 35(5).

Cousins, W., Taggart, L., \& Milner, S. (2010). Looked after or overlooked? An exploratory investigation of the mental health issues of adolescents living in state care in Northern Ireland. Psychology, health \& medicine, 15(5): 497-506.

Crane, R. S., Kuyken, W., Williams, J. M. G., Hastings, R. P., Cooper, L., \& Fennell, M. J. (2012). Competence in teaching mindfulness-based courses: concepts, development and assessment. Mindfulness, 3(1): 76-84.

Damschroder, L. J., Aron, D. C., Keith, R. E., Kirsh, S. R., Alexander, J. A., \& Lowery, J. C. (2009). Fostering implementation of health services research findings into practice: a consolidated framework for advancing implementation science. Implementation Science, 4(1): 50. DOI:10.1186/1748-5908-450.

Davidson, C., Dumigan, L., Ferguson, C., \& Nugent, P. (2011). Effective Therapeutic Approaches within Specialist Residential Childcare Settings. Child Care in Practice, 17(1): 17-35. 
Davidson, J. C. (2010). Residential care for children and young people: priority areas for change. Child Abuse Review, 19(6): 405-422.

Davren, M. (2007). Child and Adolescent Mental Health Services and the Strategic Context: The Bigger Picture. Child Care in Practice, 13(4): 327-338.

DHSSPS. (2009a). Families Matter: Regional Family and Parenting Strategy. Belfast: DHSSPS.

DHSSPS (2011a). Service Framework for Mental Health and Wellbeing. Belfast: DHSSPS.

Fearon, R. P., Bakermans-Kranenburg, M. J., Van IJzendoorn, M. H., Lapsley, A. M., \& Roisman, G. I. (2010). The Significance of Insecure Attachment and Disorganization in the Development of Children’s Externalizing Behavior: A Meta-Analytic Study. Child development, 81(2): 435-456.

Fulcher, L.C. \& Ainsworth, F. (1985). Group Care Practice with Children. London: Tavistock.

Gibbs, I., \& Sinclair, I. (1999). Treatment and treatment outcomes in children's homes. Child and Family Social Work, 4: 1-8.

Gilligan, R. (2008). Promoting resilience in young people in long-term care-the relevance of roles and relationships in the domains of recreation and work. Journal of Social Work Practice, 22(1): 3750.

Green, H., McGinnity, A., Meltzer, H., Ford, T., Goodman, R. (2005) Mental Health of Children and Young People in Great Britain, 2004. London: HMSO. 
Griffiths, M. (2003). The therapeutic use of videogames in childhood and adolescence. Clinical child psychology and psychiatry, 8(4): 547-554.

Gulliver, A., Griffiths, K. M., \& Christensen, H. (2010). Perceived barriers and facilitators to mental health help-seeking in young people: a systematic review. BMC psychiatry, 10(1): 113.

Hannon, C., Wood, C., \& Bazalgette, L. (2010). In loco parentis. Demos: London.

Havlicek, J., Garcia, A. \& Smith, D. (2013) Mental health and substance use disorders among foster care youth transitioning to adulthood: Past research and future directions. Children and Youth Services Review, 35:194-203.

Heneghan, A., Stein, R. E., Hurlburt, M. S., Zhang, J., Rolls-Reutz, J., Fisher, E Landsverk, J., McCue, S. \& Horwitz, S. M. (2013). Mental Health Problems in Teens Investigated by US Child Welfare Agencies. Journal of Adolescent Health (in press).

HSCB. (2011). Transforming Your Care: A Review of Health and Social Care in Northern Ireland. Belfast HSCB.

Iwaniec, D. (2006). (Ed.) The Child's Journey through Care: Placement Stability, Care Planning and Achieving Permanency. Chichester: Wiley.

Kato, P. M., Cole, S. W., Bradlyn, A. S., \& Pollock, B. H. (2008). A video game improves behavioral outcomes in adolescents and young adults with cancer: A randomized trial. Pediatrics, 122(2): e305e317.

Kendrick, A. (2013). Relations, relationships and relatedness: residential child care and the family metaphor. Child \& Family Social Work, 18(1): 77-86. 
Kendrick, A., Milligan, I. \& Avan, G. (2005). 'Nae too Bad': Job Satisfaction and Staff Morale in Scottish Residential Care. Scottish Journal of Residential Child Care, 4(1): 22-32.

Lewin, K. (1946). Force field analysis. Boston: Boston University.

Macdonald, G., Livingstone, N., Davidson, G., Sloan, S., Fargar, M. \& McSherry, D. (2011). Improving the Mental Health of Northern Ireland's Children and Young People: Priorities for Research. Belfast: Institute of Child Care Research.

Macdonald, G., Millen, S., \& McCann, M. (2012). Therapeutic Approaches to Social Work in Residential Child Care. London: Social Care Institute for Excellence.

Mainey, A. (2003). Better than You Think: Staff Morale, Qualifications and Retention in Residential Child Care. London: NCB.

Mainey, A. \& Crimmens, D. (2006). Fit for the Future? Residential Care in the United Kingdom. London: NCB.

McAuley, C., and Young, C. (2006) The Mental Health of Looked After Children: Challenges for CAMHS provision. Journal of Social Work Practice. 20 (1): 91 - 103.

McCann, J. B., James, A., Wilson, S., \& Dunn, G. (1996). Prevalence of psychiatric disorders in young people in the care system. BMJ: British Medical Journal, 313(7071): 1529-30.

McNiff, S. (1998). Trust the process. Boston: Shambhala Publications.

Meltzer, H., Gatward, R., Corbin, T, Goodman, R., and Ford, T. (2003). Mental Health of Young People Looked After by Local Authorities in England. London: The Stationery Office. 
Milburn, N. L., Lynch, M., \& Jackson, J. (2008). Early identification of mental health needs for children in care: a therapeutic assessment programme for statutory clients of child protection. Clinical child psychology and psychiatry, 13(1): 31-47.

MRC (Medical Research Council). (2008) Developing and evaluating complex interventions: new $\begin{array}{llll}\text { guidance. } & \text { Accessed } & \text { October }\end{array}$ http://www.mrc.ac.uk/Utilities/Documentrecord/index.htm?d=MRC004871

Mullan-Jenson, C. (2010). Being Settled and Unsettled: An IPA Study Exploring Residential Social Workers' Perceptions of Relationships with Young People in One Children's Home. Unpublished PhD Thesis, Queen’s University Belfast.

Nunno, M.A., Holden, M.J., \& Leidy, B.D. (2003). Evaluating and monitoring the impact of a crisis intervention system on a residential child care facility. Children and Youth Services Review, 25, (4): 295-315.

Petro, C., Culhane, S., Garrido, E. \& Taussig, H. (2011) Do youth in out-of-home care receive recommended mental health and educational services following screening evaluations? Children and Youth Services Review, 33: 1911-1918.

Primack, B. A., Carroll, M. V., McNamara, M., Klem, M. L., King, B., Rich, M, Chan, C. \& Nayak, S. (2012). Role of video games in improving health-related outcomes: A systematic review. American journal of preventive medicine, 42(6): 630-638.

Ruch, G. (2005). Relationship-based practice and reflective practice: holistic approaches to contemporary child care social work. Child \& Family Social Work, 10(2): 111-123. 
Saleebey, D. (Ed.). (2002). The strengths perspective in social work practice. Boston: Allyn and Bacon.

Schofield, G., \& Beek, M. (2005). Providing a secure base: Parenting children in long-term foster family care. Attachment \& human development, 7(1): 3-26.

Simons, H. (2009). Case Study Research in Practice. London: SAGE.

Skowron, E. \& Reinemann, D.H. (2005). Effectiveness of Psychological Interventions for Child Maltreatment: A Meta-Analysis. Psychotherapy: Theory, Research, Practice Training, 42 (1): 52-71.

Smith, M. L. (2009) Rethinking residential care. Bristol: The Policy Press.

Stake, R. E. (1995). The Art of Case Study Research. California: Sage.

Steckley, L., \& Smith, M. (2011). Care Ethics in Residential Child Care: A Different Voice. Ethics and Social Welfare, 5(2): 181-195.

Tarren-Sweeney, M. (2010). It's time to re-think mental health services for children in care, and those adopted from care. Clinical child psychology and psychiatry, 15(4): 613-626.

Teggart, T. \& Menary, J. (2005). An investigation of the needs of children looked after by Craigavon and Banbridge Health and Social Services Trust. Child Care in Practice, 11(1): 39-49.

Turney, D., \& Tanner, K. (2006). Therapeutic interventions for children who have experienced neglect and their families in the UK. In: C. McAuley, P. Pecora \&W. Rose (Eds.) Enhancing the WellBeing of Children and Families through Effective Interventions: UK and USA Evidence for Practice. London: Jessica Kingsley, 118-30. 
Tylee, A., Haller, D. M., Graham, T., Churchill, R., \& Sanci, L. A. (2007). Adolescent Health 6 Youth-friendly primary-care services: how are we doing and what more needs to be done? Lancet, 369(9572): 1565-73.

Uliando, A., \& Mellor, D. (2012). Maltreatment of children in out-of-home care: A review of associated factors and outcomes. Children and Youth Services Review, 34(12): 2280-86.

Unger, M. (2013). Resilience after maltreatment: The importance of social services as facilitators of positive adaptation. Child abuse \& neglect, 37(2-3): 110-15.

Utting, W., Baines, C., Stuart, M., Rowland, J. \& Vialva, R. (1997). People like us: The report of the review of the safeguards for children living away from home. London: HMSO.

VOYPIC. (2006). A Research Report on Mental Health of Looked After Children/Care Leavers in Northern Ireland. Belfast: VOYPIC.

Ward, A. (2007). Working in Group Care: Social work and social care in residential and day care settings. Bristol: BASW/Policy Press.

Whitaker, D. S., Archer, L., \& Hicks, L. (1998). Working in children's homes: Challenges and complexities. Chichester: Wiley.

Wilkinson, N., Ang, R. P., \& Goh, D. H. (2008). Online video game therapy for mental health concerns: A review. International Journal of Social Psychiatry, 54(4): 370-382.

Yin, R. (2009). Case Study Research: Design and Methods (Fourth Edition). Thousand Oaks, CA: Sage. 
